\title{
Kuva uuden ajan alun eurooppalaisista kulttuuriverkostoista tåsmentyy kirjansidostutkimuksen avulla
}

Hanna Pirinen

Liia Rebane. Lvcrec - Venus - Ivditt. Tallinner Bucheinbände zu Beginn der frühen Neuzeit. Buchbinder, Einwirkungen und Verzierungen. Taidehistorian väitöskirja, Helsingin yliopisto 2018, e-thesis https://helda.helsinki.fi/handle/10138/235220

E-kirjana julkaistut opinnäytteet ovat helpottaneet tutkimustulosten saatavuutta. Sähköinen formaatti tosin jättää viimeisen silauksen - kirjankannen - kiusallisesti puuttumaan. Näin on käynyt Liia Rebanen Helsingin yliopistossa 15.6.2018 tarkastetulle saksankieliselle kirjansidoksia käsittelevälle väitöskirjalle. Väittelijä teetti pienen, väitöspäivän jakeluun tarkoitetun painetun kirjaerän, jossa on harvinaisen oivaltavasti sommiteltu kansi. Kirjan kansikuvaksi on valittu 1500-luvulla nahkakanteen sidotun Lutherin epistolakirjan kulma yksityiskohtineen. Siinä konkretisoituvat niin kansisidosten materiaaliset ulottuvuudet kuin koristelutapojen visuaalinen maailma. Tämän lisäksi kansi kattaa jopa tekijyyteen ja omistajuuteen kytkeytyvät sosiaali- ja kulttuurihistorialliset haasteet, sillä varsinkin reformaatioajalla kirjan kaltainen ylellisyysesine mahdollisti omistajalleen julkisen tunnustuksen siitä huolimatta,

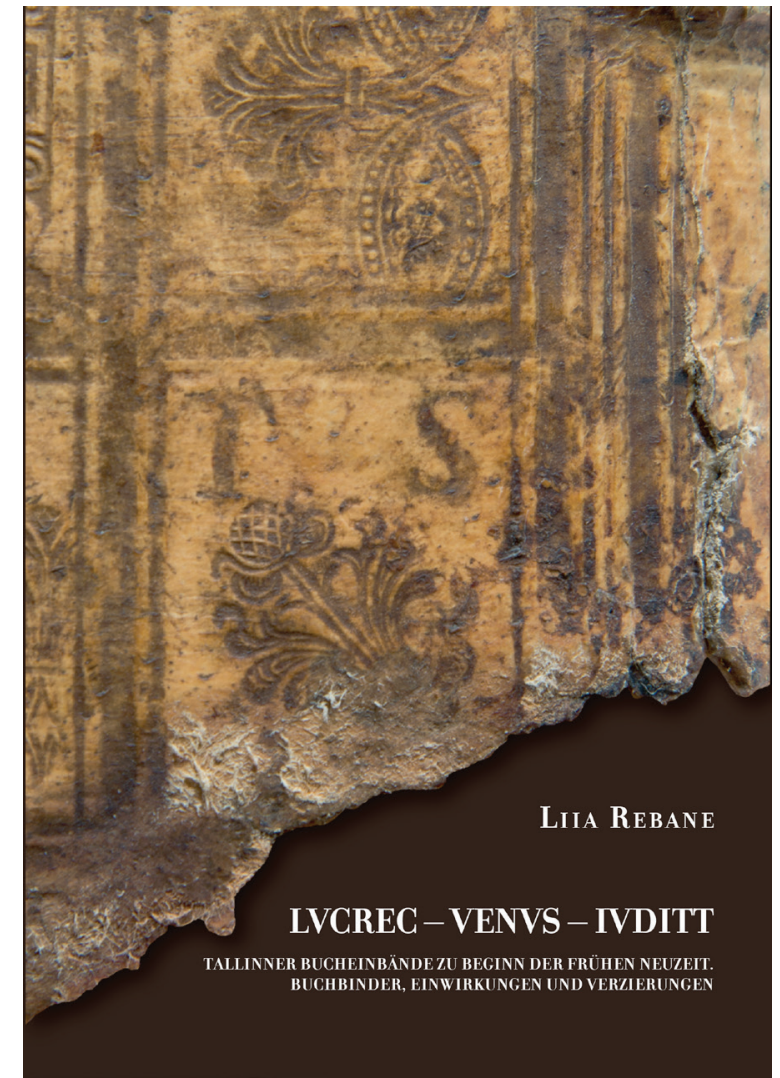


että yksityiset ajatukset olisivatkin olleet ristiriidassa julkituodun kanssa. Valitun renessanssisidoksen kulmafragmentti tulee avanneeksi myös keskustelun esineen historiallisuudesta ja todistearvosta esineenä ja konservoinnin kohteena.

Väitöstutkimuksen laajana aiheena ovat Tallinnassa säilyneet myöhäiskeskiajan ja uuden ajan alun kirjansidokset (1480-1600) ja niiden koristelu. Vahvasti empiiriseen systemaattiseen esinetutkimukseen perustuvan työn aineisto on laaja. Se koostuu noin 400:sta sidoksesta, jotka sijaitsevat eri maiden museoissa, kirjastoissa ja arkistoissa. Pääaineiston muodostavat virolaisissa kokoelmissa säilytettävät 136 sidosta, ja vertailuaineistona toimii belgialaisissa kokoelmissa 32 ja saksalaisissa yli 200 sidosta. Tutkimusraportin katalogiosuus kattaa yksityiskohtaisen inventoivan tarkastelun 59:stä sidoksesta, jotka kuuluvat tallinnalaiskokoelmiin. Väittelijä on koonnut aineistonsa ensisijaisesti tutkimusvierailuilla arkistoissa ja kirjastoissa. Aineiston muodostuminen sinänsä on kuitenkin erilaisten sattumien summa; meidän päiviimme on säilynyt se, mitä on vuosisatojen saatossa päätynyt julkisiin kirjastoihin, erityisiin kokoelmiin tai arkistoihin.

Kuten tieteellisessä tutkimuksessa yleensäkin, Liia Rebanen väitöskirjassa aineiston ja käytetyn menetelmän merkitys on ratkaiseva. Tutkielman perusjännite syntyy sattumanvaraisuuksien ja järjestelmällisyyden välisestä siteestä. Kuten yleisesti on tunnettua, ai- neistosta lähtevän tieteellisen toiminnan voi jakaa karkeasti kahteen peruslinjaan: on tutkimusta, joka tuo uusia aineistoja systemaattisen tutkimuksen piiriin ja tutkimusta, jossa jo tunnettuja aineistoja jäsennetään ja systematisoidaan uudella tavalla. Näistä Liia Rebanen tutkimus kuuluu ensisijaisesti virolaisaineiston osalta jo tunnettuun ja aiemmin tutkittuun, mutta se asettaa virolaiset sidokset osaksi laajaa kansainvälistä ilmiötä. Näin kokonaisuus tulee systemaattisen tarkastelun avulla tulkituksi ja jäsennetyksi aiemmasta poikkeavalla tavalla. Tuloksena on uusi perustellumpaan vertailuaineistoon ankkuroitu näkemys, joka muuttaa perustavanlaatuisesti aiempaa näkemystä virolaiskokoelmien kirjankansitaiteen valmistumispaikoista ja tyyliesikuvista.

\section{Kannesta kanteen - materiaalisuus ja esineellisyys} tutkimuskohteena

Liia Rebanen tutkimuksessa on kyseessä materiaalisen historian, esineen kulttuurihistorian tarkastelu. Materiaalisuuden paluuta taidehistorialliseen tutkimukseen edisti yhdysvaltalaisen David Summersin ns. neo-pragmatismi 2000-luvun alussa. Hän katsoi, etteivät taideteokset kuten muutkaan kulttuuriesineet ole ainoastaan niitä tehneiden inmisten luomuksia, vaan osa laajempaa sosiaalista ja historiallista kontekstia. Summersin kohdalla ei ole niinkään kyse asioiden erilaisista suhteellisuuksista, vaan hänen tavastaan sanallistaa tai konstruoida tulkintojaan. Materiaalinen käänne on sittemmin näkynyt 2000-luvun alkuvuosikymmenillä konferenssiteemoissa, tutkijaverkostoissa ja konkreettisessa tutkimustoiminnassa, kuten tässä virolaista kirjansidosaineistoa käsittelevässä väitöskirjassa.

Tutkimuksen kohteena on esine: kirjan tai mapin nahkapäällysteinen kansisidos taideteoksen kaltaisena kokonaisuutena. Väitöskirja kuuluu taidehistorian alaan, mutta sen ohella tutkimus on kirjahistoriaa ja etenkin kodikogiaa, joka on saanut nimensä koodeksista eli keskiaikaisesta kirjatyypistä, jossa pergamenttilehtiä on sijoitettu kansien väliin. Ranskalainen muinaiskreikan tutkija Alphonse Dain loi termin 1940-luvulla ranskalaiseksi vastineeksi saksan termille Handschriftenkunde. Kodikologia on mielletty eräänlaiseksi kirja-arkeologiaksi, jollaista Liia Rebanen kirjansidoksiin keskittyvä tutkimuskin on. Väittelijä käyttää inventoivasta sidoskartoituksestaan osuvasti termiä kodikologinen tarkastelu. Tutkimus kattaa koristelutapojen ja tekniikoiden muutokset runsaan sadan vuoden ajalta. Aineisto mahdollistaa erilaisten visuaalisten jäsennysperinteiden ja käytettyjen sidontamenetelmien muutoksen osoittamisen.

Kodikologian ohella työ on myös kirjahistoriaa, jolla puolestaan on monia tehtävänmäärittelyjä. Yhdysvaltalaisen kulttuuri- ja kirjahistorioitsija Robert Darntonin mukaan kirjahistorian tutkijan tulisi tuntea kaikkia kirjan osa-alueita, jotta tutkija voi ottaa huomioon oman tutki- 
musongelmansa kannalta oleelliset asiat ja paneutua myös itselleen vieraampiin asioihin. Haaste on melkoinen, sillä kirjanhistoriaa on mahdotonta selittää vain yhden tieteenalan näkökulmasta. Työhön tarvitaan monia tieteenaloja, tuntemusta eri kielialueista ja kirjallisista kulttuureista. Listaan voi Liia Rebanen tutkimien kirjasidosten osalta lisätä myös kuvallisen kulttuurin sekä kuvitus- ja ornamenttiperinteiden tutkimisen.

Kansisidosten tutkimuksella on systemaattista perinnettä liki sata vuotta. Edelleenkin pioneerivaiheen auktoriteettina voidaan pitää saksalaisen Konrad Haeblerin 1920-luvun lopussa ilmestynyttä tutkimusta kansikoristeluun käytetyistä rulla- ja laattaleimasimista. Vanhin tutkimusperinne keskittyi lähinnä tyylihistoriallisiin seikkoihin, ja se oli kytköksissä muuhun aikansa koristetaiteen tutkimukseen. Ala on keskittynyt sittemmin kulttuurialueille tyypillisten sidostyyppien ja niiden koristelun kehityslinjojen tunnistamiseen. Virolaisen kirjansidosten nykytutkimuksen voi katsoa alkaneen Hans Treumannin vuonna 1977 julkaisemista tuloksista. ${ }^{1}$ Työtä jatkoi Endel Valk-Falk 1990-luvulla. ${ }^{2}$ Renessanssisidosten kannalta oleelliseksi on osoittautunut saksalaisen Konrad von Rabenaun viitoittama tie. ${ }^{3}$

Liia Rebanen väitöskirjassa sidostutkimus yhdistetään kansikoristelun kautta avattaviin sisällöllisiin merkityksiin, vaikkakaan tutkimustehtävään ei ole sisällytetty varsinaista kuva-aiheiden esikuvatutkimusta. Myös yhteys 1500-luvun kirjankuvitukseen tai sa- manaikaisen graafisen taiteen kuva-aiheita soveltaviin taidekäsityön lajeihin on jätetty tarkastelun ulkopuolelle, mikä on laajan tutkimusrajauksen kannalta ymmärrettävää. Yhteyksien osoittaminen olisi kuitenkin terävöittänyt kuva-aiheiden historiallista kontekstointia. Väitöskirjassa ikonologinen tulkinta keskittyy Cesare Ripan 1500-luvun lopulla julkaiseman Iconologian luentaan aikalaiskontekstissa ja muuta aikalaiskirjallisuutta soveltaen. Myöhempää ikonografista materiaalia on käytetty, joskaan ei aina erityistä tarkkuutta osoittaen. Detaljina voi mainita, että harmillisesti pienen baijerilaisen paikallisyhteisön kunnioittama Pyhä Rosina on jäänyt huomiotta, vaikka hänen tarinansa kerrotaan tutkijan käyttämillä sivuilla Lexikon der christilichen Ikonographie -hakuteoksessa. Baijerilaiskytkös antaa pohdittavaa kirjankuvituksen ja koristeleimasinten alkuperän selvittämiseen.

\section{Esineet kaupan ja kulttuurin verkostoissa}

Itämeren rantakaupungit muodostavat monella tavoin omaleimaisen kulttuurialueen, joka on eri aikoina ollut verkostojensa kautta yhteydessä niin keskisen ja läntisen kuin itäisenkin Euroopan keskusten kanssa. Liia Rebane osoittaa ensimmäistä kertaa, että suurin osa tallinnalaisissa kokoelmissa olevista, aiemmin paikalliseksi tuotannoksi oletetuista kirjansidoksista on valmistettu Brüggessa, Antwerpenissa ja muissa Flanderin käsityöläiskeskuksissa tai saksalaisella alueella. Näin tutkimus muuttaa paikallispatrioottista käsitystä Itämeren rantakaupungeista keskuksina, jotka ovat heijastelleet vaikutustaan ensisijaisesti välittömästi ympäröivälle alueelle. Tallinnalaisaineisto asettuu aiempaa perustellumpaan ja laajempaan kauppa- ja kulttuuriverkostojen kehykseen.

Tutkimuksensa vaiheita kuvatessaan Rebane on kertonut, että brüggelaiset kansisidokset osoittautuivat tutkimuksen päänavaajiksi työn alkuvaiheessa. Tallinnalaiskokoelmissa oli kiistämättä samoja tuotteita kuin belgialaisissa arkistoissa ja kirjastoissa. Kirjansidonnan kannalta Hansaliiton ja aivan erityisesti Brüggen vaikutus osoittautui tärkeimmäksi yksittäiseksi tekijäksi 1400-luvulta 1530-luvulle. Brüggessä sijaitsi yksi Hansan neljästä kauppakonttorista. Se oli kauppaliiton tärkein finanssi- ja kauppakeskus, jossa työskenteli joukko taitavia kirjansitojia.

Hienoihin naudannahkakansiin sidottujen luksusmappien alkuperästä kielivät omaleimaisten sidontatapojen ohella alkuperää osoittavat leimat. Kansien leimakuvioinneissa esiintyvät aiheina $\mathrm{mm}$. Brabantin leijona, Antwerpenin kaupunkivaakuna ja Pyhän saksalais-roomalaisen keisarikunnan symbolit. Kansimateriaalissa on tältä osin samankaltaisia piirteitä kuin esimerkiksi alttarikaappien tarkastusleimoissa.

Flanderilaiskaupungeissa oli myynnissä valmiita kansio- tai mappisidoksia, joten asiakas saattoi ostaa paikan päällä kirjanpitotarvikkeita tai tilata niitä vaihto- 
suhdeverkostojensa kautta. Tehokkaan kauppatoiminnan ohella tämä osoittaa sen, että tallinnalaiskauppiailla ja erilaisilla paikallisyhteisöillä saattoi olla varastoissaan mappeja tulevaa tarvetta varten. Arkistonide ei siis aina muodostunut sidottamalla yhteen erillisiä asiakirjoja. Kansikoristelun aiheet olivat anonyymisti yleispäteviä. Kuva-aiheilla ei ollut henkilökohtaista, exlibrismäistä kytköstä henkilöomistajaan, eikä edes sidoksen sisällöllä ja kannen kuvituksella ollut välttämättä yhteyttä. Liia Rebanen kodikologisesti tarkastelemissa flanderilaissidoksissa koristeaiheisto liittyi ajan grafiikalle ja koristetaiteelle tyypillisiin aiheisiin. Ne hän ryhmittää kahteen pääluokkaan: figuraalisiin ja ornamentaalisiin.

Tutkimus täydentää kiinnostavasti taidealan professiotutkimusta. Attribuoiva tutkimusjuonne toteutuu inventoinnin ohessa ja saa henkilöihin tarkemmin profiloivan tarkastelun tutkimuksen viimeisessä osassa. Kirjansidonta oli Tallinnassa vielä 1500-luvun alkupuolella niin vähäistä, ettei elannokseen kirjoja sitovalle käsityöläiselle riittänyt asiakaskuntaa. Se oli oheistyö, jota yliopistokaupungeissa sidonnan oppineet pappismiehet tekivät sivutoimisesti. Olavisten kirkossa pappina 1500-luvun puolivälissä toiminut Gerth Kulemann oli ilmeisesti tällainen sivutoiminen kirjansitoja.

Uuden ajan alussa kansisidonnassa alkavat yleistyä kirjat omistajiinsa kytkevät nimikoinnit. Tallinnan rikkain mies, Urban Dene, keräsi laajan kirjakokoel- man, jolla hän ajalleen tyypilliseen tapaan representoi itselleen hyödyllisiä poliittisia ja kulttuurisesti hyödyllisiä konfessionaalisia motiiveja. Denen omistamissa wittenbergiläissidoksissa oli tyylikkäät renessanssisidokset ja näyttävästi merkitty omistajan nimi osana kansisommitelmaa. Tämän osalta kirjapaino- ja kirjankuvitusalan yksilöidympi käsittely olisi syventänyt kirjojen ensimmäisten omistajien identifioitumisen motiiveja wittenbergiläisyhteyksien osalta.

\section{Kansainvälisesti eteenpäin}

Tutkimuksellaan Liia Rebane päivittää ansiokkaasti myöhäiskeskiajan ja uuden ajan alun kulttuurimaantieteellisen verkoston ja kirjallisen kulttuurin tilannetta virolaiskokoelmien osalta. Aiemmin oletettua pienempi osa virolaisissa kokoelmissa säilyneistä kirjansidoksista on Rebanen mukaan paikallista tuotantoa. Suurin osa kirjansidoksistakin on tuotu muualta, hän osoittaa. Tulosta ei välttämättä oteta yksiselitteisen innostuneesti vastaan.

Interregionaalisten suhteiden tunnistaminen on aikaisemminkin johtanut taidehistorioitsijat kiistelemään. Varsin tuore esimerkki väittelystä liittyy ruotsalaisen konservaattori-taidehistorioitsija Peter Tångebergin tulkintaan Tukholman Suurkirkon Pyhän Yrjänän valmistajasta. Se ei olisikaan lyypekkiläismestari Berndt Notken teos, vaan flanderilainen tuontityö. ${ }^{4}$ Bernt Notken tuotannon ohella myös ham- purilaista mestari Franckea ja hänen tuotantoaan on katsottu uusin silmin ja lukemalla vähäisiä arkistolähteitä kriittisesti. Uustulkintojen seuraukset ovat olleet miedompia kuin Pyhän Yrjänän kohdalla. Oleellista mestari Franckea koskevassa tutkimuksessa on hänen varsinaisen tunnetun tuotantonsa supistuminen vain neljään teokseen ja entistä perustellummat visuaalisten vaikutteiden, kuten esimerkiksi birgittalaisuuden, leviämisestä tehdyt havainnot. ${ }^{5}$

Tallinna on ollut myös antava osapuoli eurooppalaisella taidekentällä. Viimeisimmät täsmentävät tulokset koskevat Michel Sittowia (1469-1525), tallinnalaissyntyistä Brüggessä koulutuksensa saanutta kosmopoliittitaiteilijaa, joka toimi monissa hoveissa ja jätti jälkeensä laajahkon kuvataiteellisen tuotannon. ${ }^{6}$

Liia Rebanen tutkimuksen tulokset ovat tulleet julki juuri oikealla hetkellä. Miltei kaikki nyttemmin systemaattisesti tarkastellut henkilöt tai esineryhmät osoittavat, että ammattilaiset ja niin suuret kuin pienetkin esineet liikkuivat vaivatta paikasta toiseen. Flanderilaiskeskukset vetivät puoleensa parhaita tekijöitä. Osa huippuammattilaisista valmisti myyntiin monenlaisia valmiita taidetuotteita, kuten loistokansiin sidottuja kansioita ja mappeja tai jopa moniosaisia alttarikaappeja, joita myytiin esimerkiksi brüggeläisissä kirjansitomoissa ja Antwerpenin suurilla taidemarkkinoilla. 
Kirjaa voi suositella kaikille kansiin huomiota kiinnittäville kirjahistorian ystäville. Saksankielinen väitöskirja on monelle haasteellinen lukukokemus, sillä enää varsin harvat suomalaiset kykenevät lukemaan tieteellistä saksankielistä tekstiä. Rebanen teksti on kuitenkin selkeää ja täsmällistä asiakieltä, joskin historiallisten juonteiden kehitysvaiheita olisi voinut terävöittää kirjan rakenteessa. Tämä olisi helpottanut lukijaa löytämään helpommin ilmiöiden taustan ja syntyvaiheet esimerkiksi renessanssisidosten osalta. Kirjahistorian ystävien iloksi kirjasta on tulossa uusi, tosin edelleen saksankielinen editio, joka julkaistaan Tallinnan kaupunginarkiston sarjassa.

Rebanen tutkimus Tallinnassa säilyneistä myöhäiskeskiajan ja uuden ajan alun kirjansidoksista ja niiden koristelusta on alallaan tärkeä virstanpylväs. Tallinnalaismateriaalia koskeva kirjansidostutkimus ansaitsisi jatkoa laajempana pohjoismaisena hankkeena. On toivottavaa, että ansionsa alan asiantuntijana osoittanut väittelijä löytäisi yhteistyökumppaneita taide- ja kulttuurihistoriallisesti tärkeään kulttuuriperintöhankkeeseen.

\section{Viitteet}

1 Hans Treumann, Vanemast raamatukultuuriloost (Tallinn: Eesti Raamat, 1977).

2 Ks. esim. Endel Valk-Falk, Tallinna köiteuunikume. Kunstist Eestis läbi aegade. Uurimusi ja artikleid.

Koost. Irina Solomõkova (Tallinn: Kunst, 1990) 195-

211; Endel Valk-Falk, Verba volant, scripta manent.
Jutt lendab tuulde, kirjutatu jääb. Valik raamatuajalooalaseid uurimuslikke kirjutisi autori redaktsioonis (Tartu Kõrgema Kunstikooli

toimetised 8. Tartu: Tartu Kõrgem Kunstikool, 2008). 3 Ks. esim. Konrad von Rabenau, „Wittenberger Einbandkunst im 16. Jahrhundert", teoksessa Vier Beobachtun- gen. 700 Jahre Wittenberg. Stadt, Universität, Reformation (Hrsg. Stefan Oehmig. Weimar: Böhlau, 1995) 365-384.

4 Tångeberg, Peter, Wahrheit und Mythos. Bernt Notke und die Stockholmer St.-Georgs-Gruppe. Studien zu einem Hauptwerk niederländischer Bildschnitzerei. Ostfildern: Thorbecke, 2009; kirjaarvostelu Pirinen, Hanna, "Myyttinen Bernt Notke", Tahiti nro 1 (2011) Luettu 30.1.2018. http://tahiti. fi/01-2011//kirja-arvostelut/myyttinen-bernt-notkel/; Svanberg, Jan, "Was the St George group in Stockholm made in Antwerp by an unknown Flemish master?" Art, cult and patronage. Die visuelle Kultur im Ostseeraum zur Zeit Bernt Notkes. Toim. Anu Mänd \& Uwe Albrecht. Kiel: Verlag Ludwig, 2013, 323-329.

5 Meister Francke Revisited: Auf den Spuren eines Hamburger Malers Toim. Ulrike Nürnberger, Elina Räsänen \& Uwe Albrecht. Petersberg: Michael Imhof Verlag, 2017; Kirja-arvostelu Pirinen, Hanna, " Monitieteistä tutkimusta mestari Franckesta", Tahiti

Vol 8 Nro 1 (2018) Luettu 3.9.2018. https://tahiti. journal.fi/article/view/69296/30750.

6 Tallinnan Kumussa vuonna 2018 järjestettyyn näyttelyyn liittyy julkaisu Koppel, Greta, Michel Sittow. Eesti maalikunstnik Euroopa õukondades. Eesti Kunstimuuseum, 2018
Dosentti Hanna Pirinen tyo̊skentelee yliopistotutkijana Jyvåskylän yliopistossa. Hän on tutkinut erityisesti 1500- ja 1600-luvun taiteen aatteellisia taustoja ja esineellisiå ilmio̊itå. Viime vuosina hån on myo̊s edistånyt taidehistoriallisen, ma-

teriaalitieteellisen ja optisia menetelmiå soveltavan tutkimuksen kaupallistamista monitieteisesså taideteostutkimushankkeessa, josta on syntynyt tutkimustoimintaa harjoittava yritys RECENART Oy.



